\title{
Promotion of Keratinocyte Proliferation by Tracheloside through ERK1/2 Stimulation
}

\author{
JaeGoo Kim $\mathbb{D}^{1},{ }^{1}$ Yu-Kyong Shin, ${ }^{2}$ and Ki-Young Kim $\mathbb{D}^{1,2}$ \\ ${ }^{1}$ Graduate School of Biotechnology, Kyung Hee University, Yongin-si, Gyeonggi-do, Republic of Korea \\ ${ }^{2}$ College of Life Science, Kyung Hee University, Yongin-si, Gyeonggi-do, Republic of Korea \\ Correspondence should be addressed to Ki-Young Kim; kiyoung@khu.ac.kr
}

Received 28 May 2018; Accepted 17 July 2018; Published 26 July 2018

Academic Editor: Christian Agyare

Copyright (c) 2018 JaeGoo Kim et al. This is an open access article distributed under the Creative Commons Attribution License, which permits unrestricted use, distribution, and reproduction in any medium, provided the original work is properly cited.

\begin{abstract}
Cell migration and proliferation are important for proper wound healing after skin injury. Recent studies have shown that compounds from plants could promote cell migration and proliferation. Tracheloside, which is a plant lignan, has been found to promote the growth of $\mathrm{HaCaT}$ cells over $40 \%$ compared to other compounds tested based on a cell proliferation assay. An in vitro scratch assay confirmed the healing activity of tracheloside (more than 2 -fold increased healing activity after 24 hours of treatment compared with the control) and revealed that this activity is better than that of allantoin (1.2-fold increased after 24 hours of treatment compared with the control), a positive control. With western blot results, wound healing with tracheloside occurred through the phosphorylation of ERK1/2. Therefore, tracheloside is a good candidate to promote wound healing and could be developed as a therapeutic agent for wound treatment or used as a leading compound with higher activity.
\end{abstract}

\section{Introduction}

Skin wound healing is a complex process involving the reepithelialization of missing cellular structures and tissue layers through three phases: inflammation, proliferation, and remodeling. Of the many cell types required during the wound healing process, keratinocytes are important for epithelialization in the proliferative phase as they are the predominant cell of the outermost layer of the skin. In addition, complex interactions and cross communication between keratinocytes and other cell types during all three phases of wound healing are critical for successful wound closure and repair $[1,2]$.

As keratinocytes proliferate and migrate toward the upper layers of the epidermis, they are differentiated and transformed through different cell layers to reach their final maturation stage [3]. Cell proliferation is activated by growth factors and cytokines that are released into the injury site. Combined key events such as signaling, cytoskeletal reorganization, and adhesion processes are required [4].

Mitogen-activated protein (MAP) kinase family members such as ERK1/2, JNK, and p38 are well known for their importance in wound healing, cell survival, differentiation, and proliferation $[5,6]$. The major mechanism in these processes is the regulation of cell cycle entry and progression. For example, ERK1/2 regulates cyclin D1, which controls cell proliferation $[7,8]$.

Tracheloside, which belongs to plant lignans, is a component of Trachelospermum jasminoides used as herbal medicines in Japan, China, and Korea. It is already known that plant lignans have various effects related to growth factor actions, steroid biosynthesis, cell differentiation, cell transformation, and proliferation [9-11].

In the present experiment, we showed the effect of tracheloside on keratinocyte proliferation. To confirm this effect, we used a scratch wound healing assay, cell proliferation assay, and western blot analysis for signaling related to cell proliferation.

\section{Materials and Methods}

2.1. Chemicals. All plant extracts were purchased from ChemFaces (Wuhan, China), and the tracheloside chemical structure is shown in Figure 1. Allantoin as a positive control 


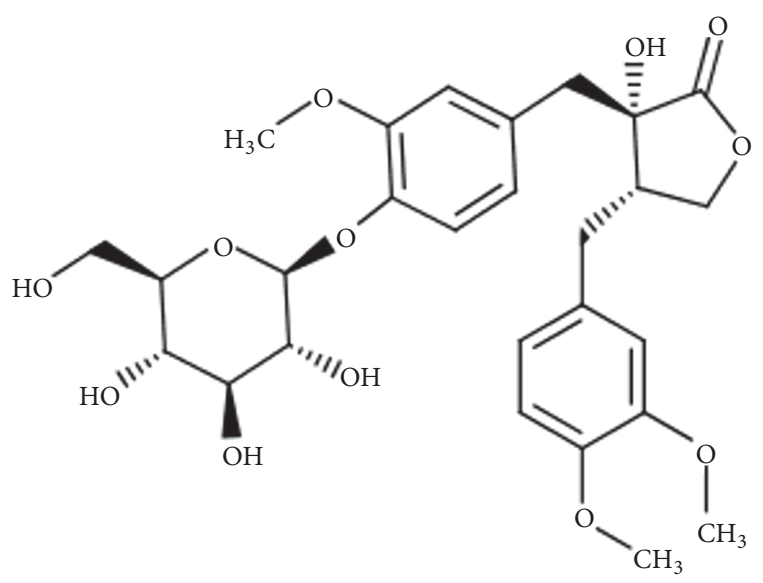

FIGURE 1: Structure of tracheloside.

was obtained from Sigma-Aldrich (St. Louis, MO, USA) $[12,13]$. The chemicals were dissolved in dimethyl sulfoxide (DMSO), and the stock solutions were stored at $-20^{\circ} \mathrm{C}$.

2.2. Animal Cells and Culture. Human keratinocyte cell line $\mathrm{HaCaT}$ were maintained in Dulbecco's Modified Eagle's Medium (DMEM) containing 10\% Fetal Bovine Serum (FBS) and $1 \%$ penicillin-streptomycin at $37^{\circ} \mathrm{C}$ in a $5 \% \mathrm{CO}_{2}$ atmosphere [14].

2.3. Cell Proliferation Assay. The proliferation of $\mathrm{HaCaT}$ cells by test compounds was tested using a slightly modified cellbased MTT assay [14]. HaCaT cells in DMEM were added to the wells of a 96-well plate at a density of $10^{3}$ cells per well. Serum-free medium including various concentrations of tracheloside $(0,1,5,10,50$, and $100 \mu \mathrm{g} / \mathrm{ml})$ were added and further incubated for 48 hours. MTT (3-(4,5-dimethyl-thiazol2-yl)-2,5-diphenyltetrazolium bromide, Sigma) in PBS was added into each well at a final concentration of $0.5 \mathrm{mg} / \mathrm{ml}$, followed by incubation for 3 hours at $37^{\circ} \mathrm{C}$. The medium was then removed, and cells were suspended in $100 \mu \mathrm{l}$ DMSO for 10 minutes. Cell proliferation was calculated from optical density $\left(\mathrm{OD}_{540}\right)$ values measured using a microplate reader (BioTek Instruments, Korea) and were reported as a percentage of the vehicle control $[14,15]$.

2.4. In Vitro Wound Healing. HaCaT cells were seeded into 6-well plate and cultured to nearly confluent cell monolayers. A linear vertical and horizontal wound was then generated in the monolayer with a sterile $20-200 \mu$ l plastic pipette tip. Any cellular debris was removed by washing with phosphate-buffered saline (PBS). Serum-free medium with various concentrations of tracheloside $(1,5$, and $10 \mu \mathrm{g} / \mathrm{ml})$ was added in triplicate and incubated for 24 hours at $37^{\circ} \mathrm{C}$ with $5 \% \mathrm{CO}_{2}$ atmosphere. Images of the scratched areas were photographed to estimate the relative proliferation of cells at 0 and 24 hours posttreatment. The data were analyzed using an EVOS XL imaging system (Fisher Scientific, USA) by calculating the percentage of scratch closure at each dose

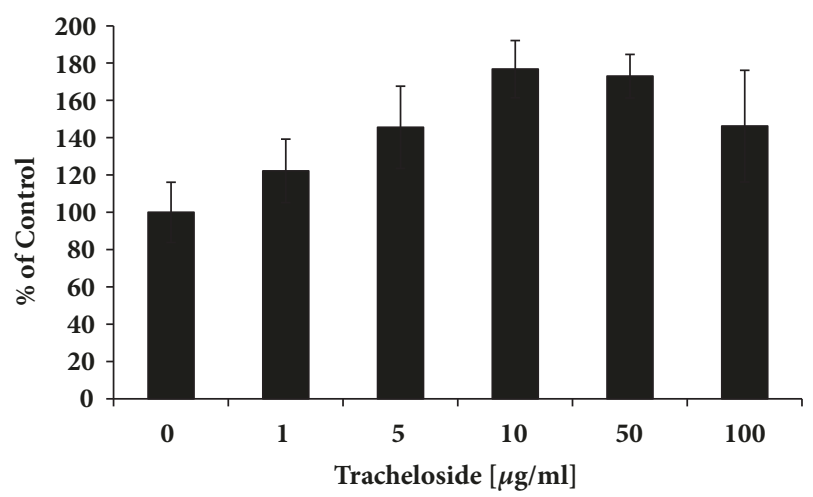

FIgURE 2: Tracheloside induced the cell proliferation rate. Various concentrations of tracheloside were applied to HaCaT cells cultured for 24 hours in serum-free medium and checked the cell proliferation rate using MTT.

point relative to the control. The experiments were repeated three independent times [15].

2.5. Western Blot Analysis. Protein was extracted with RIPA buffer and quantified with the Bradford reagent (Sigma). Protein samples with equal amounts $(25 \mu \mathrm{g})$ were separated by 8 $10 \%$ SDS-PAGE and transferred onto polyvinylidene fluoride (PVDF, Bio-Rad, USA) membranes. The membranes were blocked with $5 \%$ bovine serum albumin (BSA, GenDEPOT, Korea) and then incubated with a 1:2000 dilution of primary antibodies (p38 $\alpha$, p-p38, ERK1/2, JNK, p-JNK, and GAPDH from Santa Cruz Biotechnology, CA, USA; p-ERK1/2 from Cell Signaling Technology, MA, USA) overnight at $4^{\circ} \mathrm{C}$. The membranes were washed with TBST and incubated with a secondary horseradish-peroxidase-conjugated antibody for 1 hour at room temperature. The membranes were developed using enhanced ECL (Bio-Rad, USA) on a UVITEC imaging system (UVITEC Cambridge, UK). Each experiment was repeated at least twice for consistency of the results [7].

2.6. Statistical Analysis. Results are expressed as means \pm SD. Statistically significant differences were analyzed with oneway ANOVA with Tukey's post hoc test.

\section{Results}

3.1. Enhanced Cell Growth Effect of Tracheloside to Keratinocytes. Several available extracts from plants were used to test and compare their effects of proliferation to keratinocyte $\mathrm{HaCaT}$ cells (Table 1). It was found that tracheloside increased cell proliferation against human cells (Figure 2).

In $10 \mu \mathrm{g} / \mathrm{ml}$ concentration, $\mathrm{HaCaT}$ cells grew over $45.58 \%$ more compared to the control.

3.2. Tracheloside Increased Wound-Healing. To determine the effect of tracheloside on keratinocyte proliferation, various concentrations of tracheloside were used to treat $\mathrm{HaCaT}$ cells. Tracheloside increased the proliferation of $\mathrm{HaCaT}$ cells in a dose-dependent manner (Table 2 and Figure 3 ) compared to 
TABLE 1: Cell proliferation effect of several plant extracts (\% of control).

\begin{tabular}{lccc}
\hline Compounds & $\begin{array}{c}\text { Proliferation rate } \\
(100 \mu \mathrm{g} / \mathrm{ml})\end{array}$ & Compounds & $\begin{array}{c}\text { Proliferation rate } \\
(100 \mu \mathrm{g} / \mathrm{ml})\end{array}$ \\
\hline Bisdemethoxy-curcumin & $2.60 \pm 0.70$ & Falcarindiol & $27.71 \pm 0.79$ \\
Sophoraflavanone G & $0.97 \pm 0.13$ & Pimaric acid & $81.11 \pm 5.35$ \\
Acetylshikonin & $30.42 \pm 5.36$ & Anwulignan & $103.59 \pm 1.36$ \\
Lobatoside C & $2.40 \pm 1.25$ & 6,8 -Diprenylorobol & $3.69 \pm 0.05$ \\
Alpinumisoflavone & $73.56 \pm 4.09$ & Galangin & $113.66 \pm 3.01$ \\
Eupatilin & $78.30 \pm 1.73$ & Corosolic acid & $72.59 \pm 3.27$ \\
Kurarinone & $10.49 \pm 0.49$ & Tracheloside & $145.58 \pm 22.1$ \\
\hline
\end{tabular}

TABLE 2: Tracheloside increased wound healing after 24 hours of treatment through an in vitro scratch assay.

\begin{tabular}{lccr}
\hline Concentration of treatment & \multicolumn{3}{c}{ \% of wound healing from 0 hours } \\
& Control & Tracheloside & $13.55 \pm 2.38$ \\
$1 \mu \mathrm{g} / \mathrm{ml}$ & $10.12 \pm 1.29$ & $13.98 \pm 3.21$ & $12.33 \pm 2.26$ \\
$5 \mu \mathrm{g} / \mathrm{ml}$ & $9.13 \pm 1.94$ & $18.82 \pm 5.95$ & 12.39 \\
$10 \mu \mathrm{g} / \mathrm{ml}$ & $10.38 \pm 0.19$ & $17.94 \pm 2.03$ & $12.50 \pm 2.42$ \\
\hline
\end{tabular}

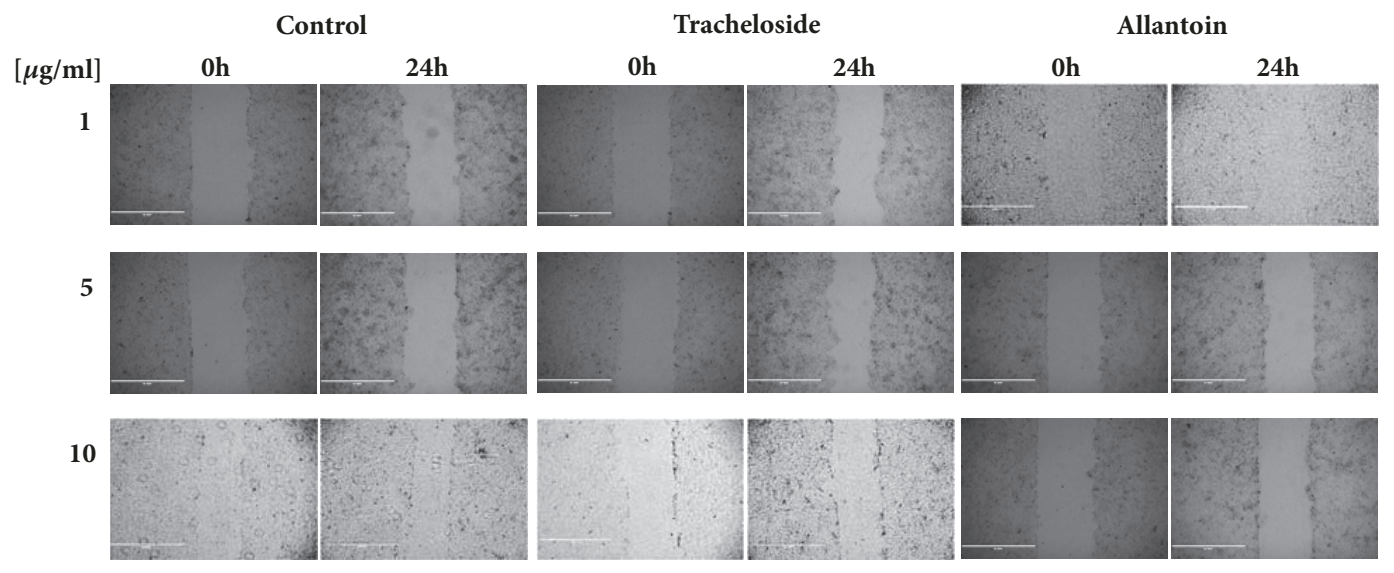

FIGURE 3: Effect of tracheloside on the proliferation of HaCaT cells through the wound healing assay. HaCaT cells were cultured in a 6well plate, scratched, and treated with different concentrations of DMSO only, allantoin, or tracheloside. The results were photographed and demonstrated healing of the scratched wound with various concentrations of compounds.

the control or allantoin as a positive control. Tracheloside increased the cell proliferation rate by $13.98 \%, 18.82 \%$, and $17.94 \%$ at 1,5 , and $10 \mu \mathrm{g} / \mathrm{ml}$, respectively after 24 -hour treatment. As a result of those findings, 38.14\%, 106.13\%, and $72.83 \%$ increased healing activity was observed, respectively, compared with the control.

3.3. Tracheloside Induced ERK1/2 Phosphorylation. Tracheloside treatment promoted the proliferation of HaCaT cells. To investigate whether signaling kinases including p38, JNK, and ERK1/2 participated in proliferation, western blot analysis was performed after treatment with tracheloside (Figures 4(a) and 4(b)). Phosphorylated ERK1/2 increased dose-dependently 1.3-, 1.67-, and 2.73-fold by 1,50 , and 10 $\mu \mathrm{g} / \mathrm{ml}$, but phosphorylated JNK was slightly decreased and phosphorylated p38 did not show any change after treatment with tracheloside.

\section{Discussion}

Tracheloside is a type of plant lignan and an analogue of another plant lignan, arctiin. Arctiin has exhibited some clinical effects including anti-inflammatory, improved immune response to influenza, and antidiabetic activities [16-18]. However, arctiin has also shown antiproliferative effects [19, 20]. Tracheloside is a known antiestrogenic lignan [21]. Other effects of tracheloside have yet to be found.

In the present study, we showed that tracheloside positively affects the proliferation of the keratinocyte, $\mathrm{HaCaT}$, which is comparable with allantoin as the positive control, which exhibited less effect on cell proliferation than tracheloside [12].

ERK1/2, one of the MAP kinase family members, are phosphorylated and activated by MEK, a tyrosine/threonine 


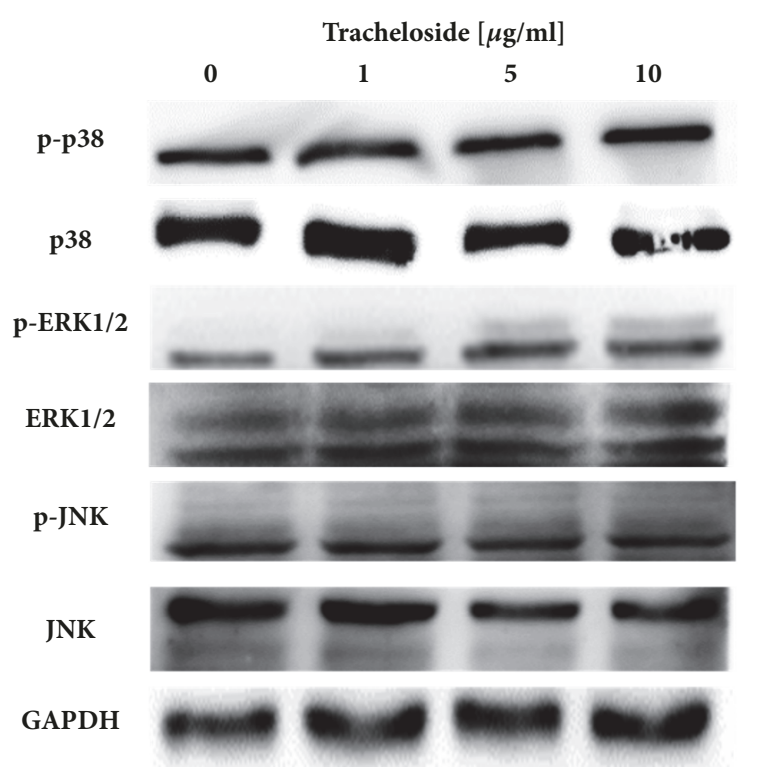

(a)

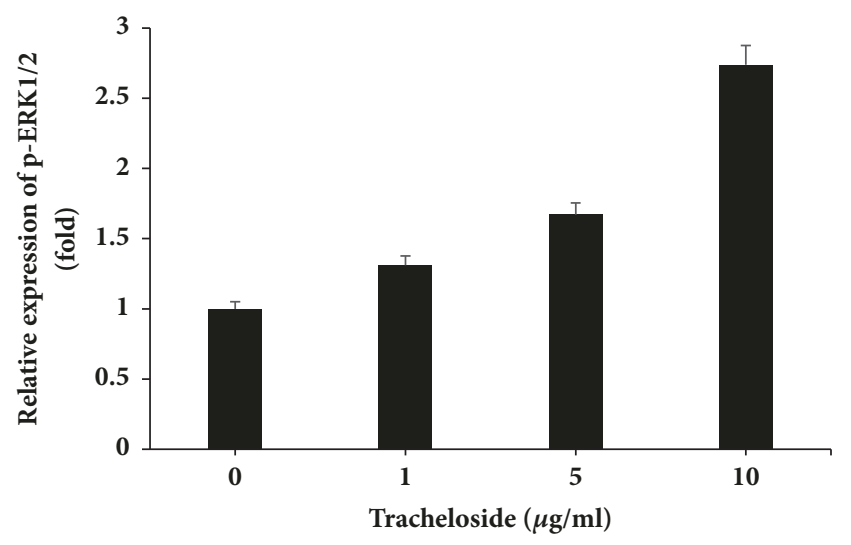

(b)

FIGURE 4: Tracheloside dose-dependently induced ERK1/2 phosphorylation on the HaCaT cells. HaCaT cells were treated with various concentration of tracheloside and the protein was used in western blot analysis. (a) GAPDH was used as a control, and p38, ERK1/2, and JNK, which are related with cell proliferation in their phosphorylated forms, were detected. (b) The p-ERK1/2 was quantified with densitometric analysis and normalized with GAPDH.

kinase [22]. Activated ERK1/2 (p-ERK1/2) can change extracellular stimulus to intracellular signal that control gene expression, which contributes to the regulation of cell proliferation [23]. Western blot results show that phosphorylation of ERK1/2 was increased as tracheloside was treated. Therefore, tracheloside affects proliferation through the regulation of ERK1/2 phosphorylation [6, 7].

In vivo testing and experiments with epidermal tissue were not performed in this study. These additional data will show a clearer effect of tracheloside in cell proliferation. Based on our research results, tracheloside could be recommended as a lead compound related to wound healing and skin proliferation. Western blot analysis under a pathway of ERK1/2 and RT-PCR results about interleukins will aid in the understanding of how tracheloside stimulates keratinocytes [24-26].

In conclusion, tracheloside can be used as a good candidate to promote wound healing. Furthermore, it could be utilized as therapeutic uses for wound treatment.

\section{Data Availability}

The data used to support the findings of this study are available from the corresponding author upon request.

\section{Conflicts of Interest}

The authors declare that the research was conducted in the absence of any commercial or financial relationships that could be construed as potential conflicts of interest.

\section{Acknowledgments}

This research was supported by the Basic Science Research Program through the National Research Foundation of Korea (NRF) funded by the Ministry of Education (NRF2015R1D1A1A01061225).

\section{References}

[1] W. K. Stadelmann, A. G. Digenis, and G. R. Tobin, "Physiology and healing dynamics of chronic cutaneous wounds," The American Journal of Surgery, vol. 176, no. 1, pp. 26S-38S, 1998.

[2] Z. Wang, Y. Wang, F. Farhangfar, M. Zimmer, and Y. Zhang, "Enhanced keratinocyte proliferation and migration in coculture with fibroblasts," PLOS ONE, vol. 7, no. 7, Article ID e40951, 2012.

[3] J. Jean, J. Soucy, and R. Pouliot, "Effects of retinoic acid on keratinocyte proliferation and differentiation in a psoriatic skin model," Tissue Engineering Part A, vol. 17, no. 13-14, pp. 18591868, 2011.

[4] D. J. Webb, J. T. Parsons, and A. F. Horwitz, "Adhesion assembly, disassembly and turnover in migrating cells-over and over and over again," Nature Cell Biology, vol. 4, no. 4, pp. E97-E100, 2002.

[5] C. Martínez-Mora, A. Mrowiec, E. M. García-Vizcaíno, A. Alcaraz, J. L. Cenis, and F. J. Nicolás, "Fibroin and sericin from Bombyx mori silk stimulate cell migration through upregulation and phosphorylation of c-Jun," PLoS ONE, vol. 7, no. 7, Article ID e42271, 2012.

[6] Y. Sun, W. Z. Liu, T. Liu, X. Feng, N. Yang, and H. F. Zhou, "Signaling pathway of MAPK/ERK in cell proliferation, differentiation, migration, senescence and apoptosis," Journal of Receptors and Signal Transduction, vol. 35, no. 6, pp. 600-604, 2015. 
[7] G.-D. Sharma, J. He, and H. E. P. Bazan, "p38 and ERK1/2 coordinate cellular migration and proliferation in epithelial wound healing," The Journal of Biological Chemistry, vol. 13, no. 24, pp. 21989-21997, 2003.

[8] J. Rodríguez, F. Calvo, J. M. González, B. Casar, V. Andrés, and P. Crespo, "ERK1/2 MAP kinases promote cell cycle entry by rapid, kinase-independent disruption of retinoblastoma-lamin A complexes," The Journal of Cell Biology, vol. 191, no. 5, pp. 967979, 2010.

[9] Y. Kitamura, M. Yamagishi, K. Okazaki et al., "Lack of significant inhibitory effects of a plant lignan tracheloside on 2-amino-1-methyl-6-phenylimidazo[4,5-b]pyridine (PhIP)-induced mammary carcinogenesis in female Sprague-Dawley rats," Cancer Letters, vol. 200, no. 2, pp. 133-139, 2003.

[10] H. Adlercreutz, B. R. Goldin, S. I. Gorbach et al., "Soybean phytoestrogen intake and cancer risk," Journal of Nutrition, vol. 125, pp. 757S-770S, 1995.

[11] H. Adlercreutz, "Phytoestrogens and prevention of cancer," Food Factors for Cancer Prevention, pp. 587-592, 1997.

[12] V. L. Savic, V. D. Nikolic, I. A. Arsic et al., "Comparative Study of the Biological Activity of Allantoin and Aqueous Extract of the Comfrey Root," Phytotherapy Research, vol. 29, no. 8, pp. 1117$1122,2015$.

[13] L. U. Araújo, A. Grabe-Guimarães, V. C. F. Mosqueira, C. M. Carneiro, and N. M. Silva-Barcellos, "Profile of wound healing process induced by allantoin," Acta Cirurgica Brasileira, vol. 25, no. 5, pp. 460-466, 2010.

[14] Y. K. Shin and K. Y. Kim, "Macelignan inhibits bee pathogenic fungi Ascophaera apis growth through HOG1 pathway," Brazilian Journal of Medical and Biological Research, vol. 47, no. 7, Article ID e5313, 2016.

[15] O. di Martino, A. Tito, A. De Lucia et al., "Hibiscus syriacus Extract from an Established Cell Culture Stimulates Skin Wound Healing," BioMed Research International, vol. 2017, Article ID 7932019, 9 pages, 2017.

[16] S. Lee, S. Shin, K. Kim et al., "Anti-inflammatory function of arctiin by inhibiting COX-2 expression via NF- $\kappa$ B pathways," Journal of Inflammation, vol. 8, no. 1, p. 16, 2011.

[17] K. Hayashi, K. Narutaki, Y. Nagaoka, T. Hayashi, and S. Uesato, "Therapeutic effect of arctiin and arctigenin in immunocompetent and immunocompromised mice infected with influenza A virus," Biological \& Pharmaceutical Bulletin, vol. 33, no. 7, pp. 1199-1205, 2010.

[18] L.-C. Lu, W. Zhou, Z.-H. Li et al., "Effects of arctiin on streptozotocin-induced diabetic retinopathy in sprague-dawley rats," Planta Medica, vol. 78, no. 12, pp. 1317-1323, 2012.

[19] S. Y. Ryu, J. W. Ahn, Y. H. Kang, and B. H. Han, "Antiproliferative effect of arctigenin and arctiin," Archives of Pharmacal Research, vol. 18, no. 6, pp. 462-463, 1995.

[20] Y. Matsuzaki, M. Koyama, T. Hitomi et al., "Arctiin induces cell growth inhibition through the down-regulation of cyclin D1 expression," Oncology Reports, vol. 19, no. 3, pp. 721-727, 2008.

[21] H. H. Yoo, J. H. Park, and S. W. Kwon, "An anti-estrogenic lignan glycoside, tracheloside, from seeds of Carthamus tinctorius," Bioscience, Biotechnology, and Biochemistry, vol. 70, no. 11, pp. 2783-2785, 2006.

[22] L. Zhao and R. D. Brinton, "Vasopressin-induced cytoplasmic and nuclear calcium signaling in embryonic cortical astrocytes: Dynamics of calcium and calcium-dependent kinase translocation," The Journal of Neuroscience, vol. 23, no. 10, pp. 4228-4239, 2003.
[23] S. Barbero, A. Bajetto, R. Bonavia et al., "Expression of the chemokine receptor CXCR4 and its ligand stromal cell-derived factor 1 in human brain tumors and their involvement in glial proliferation in vitro," Annals of the New York Academy of Sciences, vol. 973, pp. 60-69, 2002.

[24] L. Wu, X. Chen, J. Zhao et al., "A novel IL-17 signaling pathway controlling keratinocyte proliferation and tumorigenesis via the TRAF4-ERK5 axis," The Journal of Experimental Medicine, vol. 212, no. 10, pp. 1571-1587, 2015.

[25] M. M. McFarland-Mancini, H. M. Funk, A. M. Paluch et al., "Differences in wound healing in mice with deficiency of IL6 versus IL-6 receptor," The Journal of Immunology, vol. 184, no. 12, pp. 7219-7228, 2010.

[26] Y. Zhang, T. Kobayashi, Y. Hayashi et al., "Important role of epiregulin in inflammatory responses during corneal epithelial wound healing," Investigative Ophthalmology \& Visual Science, vol. 53, no. 4, pp. 2414-2423, 2012. 


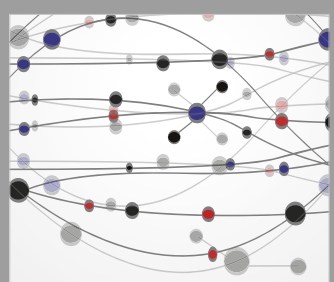

The Scientific World Journal
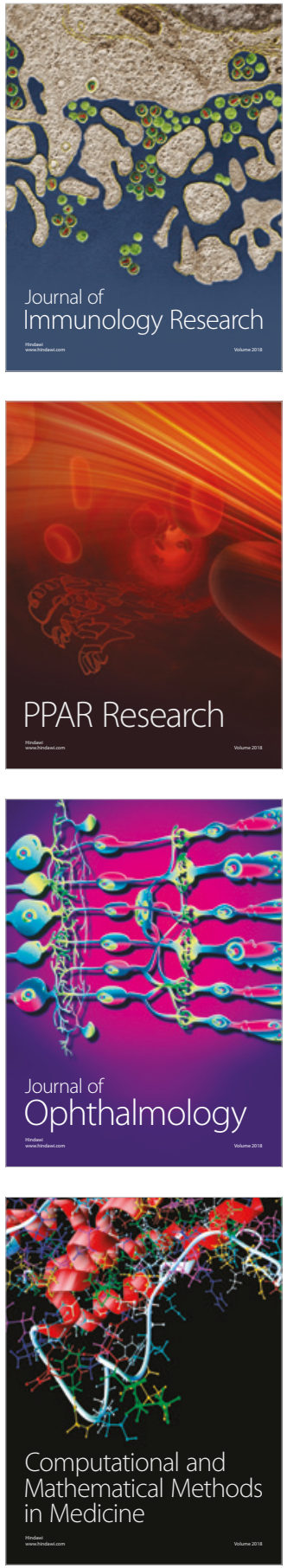

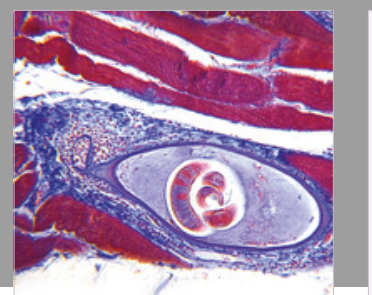

Gastroenterology Research and Practice

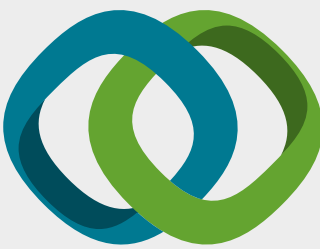

\section{Hindawi}

Submit your manuscripts at

www.hindawi.com
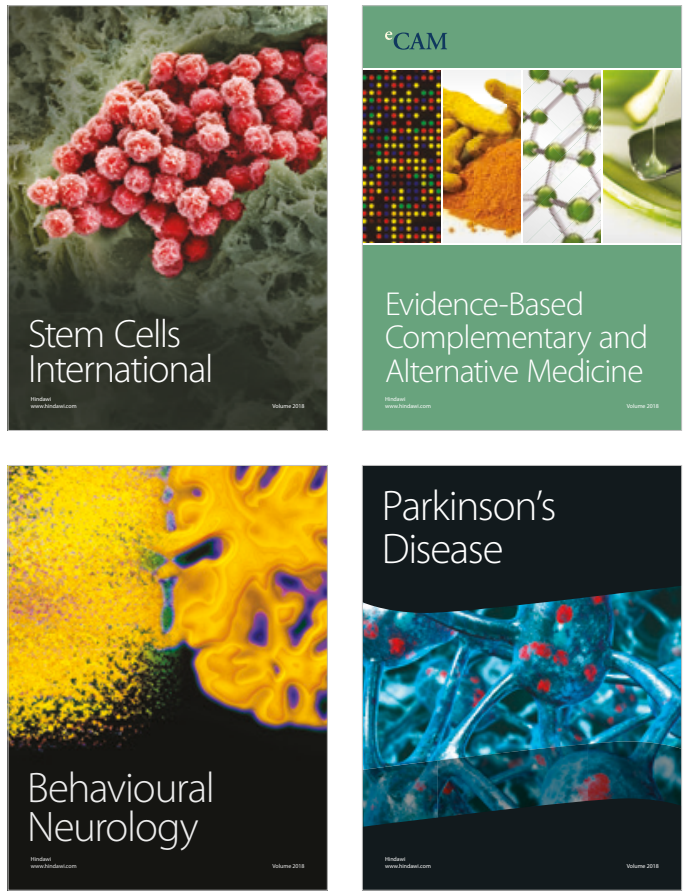

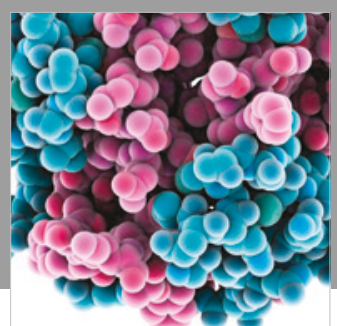

ournal of

Diabetes Research

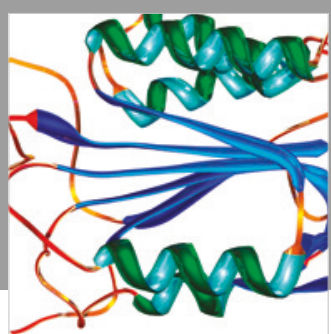

Disease Markers
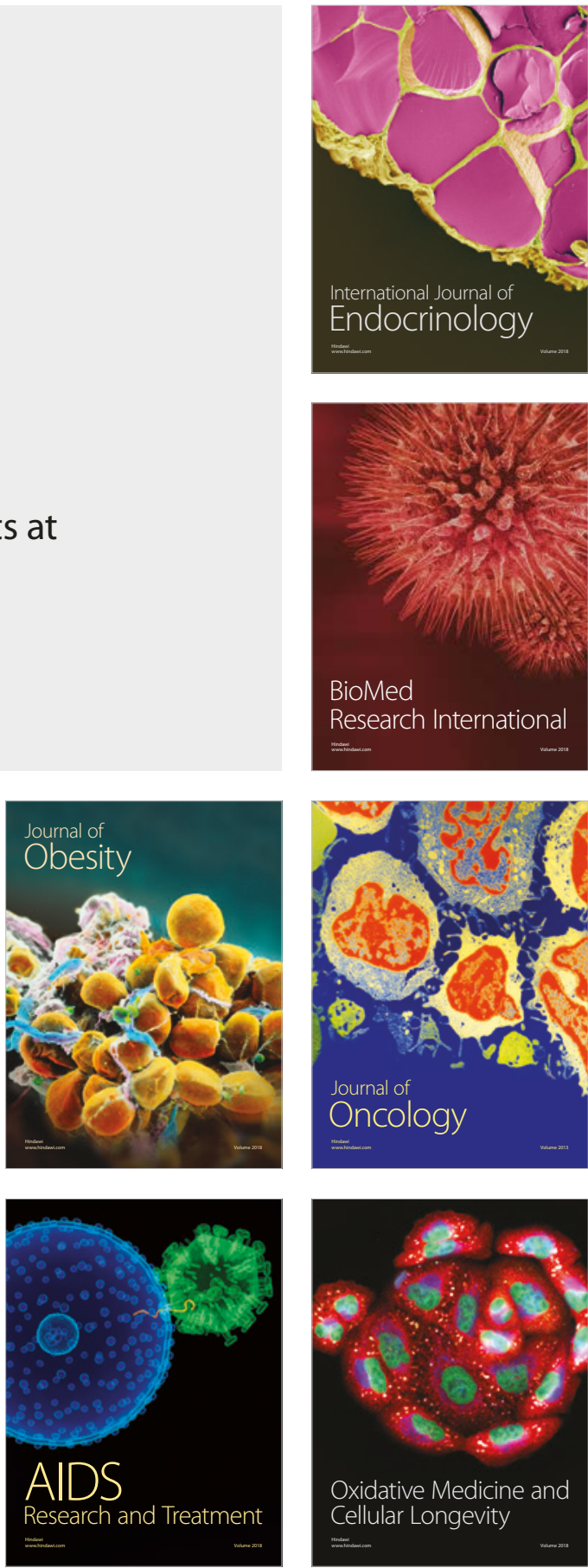